\title{
Evolução de manifestações patológicas em edificações escolares após vinte anos de exposição
}

\author{
Milton Paulino. Costa Junior ${ }^{1 *}$, Lucas Friedrich. Behrend ${ }^{2}$, Geilma Lima. Vieira ${ }^{3}$ \\ *Autor de Contacto: milton.paulino@gmail.com \\ ${ }^{1}$ Departamento de engenharia civil, Universidade Federal do Espírito Santo, Universidad o Institución, Vitória-ES, \\ Brasil \\ ${ }^{2}$ Departamento de engenharia civil, Universidade Federal do Espírito Santo, Universidad o Institución, Vitória-ES, \\ Brasil \\ ${ }^{3}$ Departamento de engenharia civil, Universidade Federal do Espírito Santo, Universidad o Institución, Vitória-ES, \\ Brasil
}

\begin{abstract}
RESUMO
As manifestações patológicas em edificações de instituições de ensino geram, além do desconforto visual, a possibilidade de prejuízos ligados à realização das atividades acadêmicas e à segurança de seus usuários. O objetivo do trabalho é identificar e analisar como essas manifestações patológicas evoluíram após 20 anos, desde o primeiro levantamento, realizado em 2001. Para o levantamento adotou-se a metodologia da norma de inspeção predial do Ibape. A inspeção predial seguindo essa norma tem como objetivo a avaliação das condições técnicas, de uso, operação, manutenção e funcionalidade de uma edificação. Observou-se nos resultados que em alguns casos, houve o aumento do estado de degradação nos materiais presentes em alguns sistemas construtivos, com variações principalmente na quantidade de manchas de umidade e bolor verificadas.
\end{abstract}

Palabras clave: manifestações patológicas, construção civil, instituição de ensino. 


\title{
Evolución de las manifestaciones patológicas en los edificios escolares después de veinte años de exposición
}

\begin{abstract}
RESUMEN
Las manifestaciones patológicas en los edificios de las instituciones educativas generan, además del malestar visual, la posibilidad de pérdidas relacionadas con el desempeño de las actividades académicas y la seguridad de sus usuarios. El objetivo del trabajo es identificar y analizar cómo evolucionaron las patologías después de 20 años, desde el primer relevamiento, realizado en 2001. El relevamiento de patologías se realizó utilizando la metodología estándar de inspección de edificios Ibape. La inspección de edificios siguiendo esta norma tiene como objetivo evaluar las condiciones técnicas, el uso, la operación, el mantenimiento y la funcionalidad de un edificio. Se observó en los resultados que en algunos casos se produjo un aumento del estado de degradación de los materiales presentes en algunas patologías, con variaciones principalmente en la cantidad de humedad y manchas de moho comprobadas.
\end{abstract}

Palabras clave: Patología de la construcción, construcción civil, institución educativa.

\section{Evolution of pathological manifestations in school buildings after twenty years of exposure}

\begin{abstract}
Pathological manifestations in edifices of educational institutions generate, in addition to visual discomfort, the possibility of losses related to the performance of academic activities and the safety of their users. The objective of the work is to identify and analyze how pathologies evolved after 20 years, since the first survey, carried out in 2001. The survey of pathologies was carried out using the Ibape building inspection standard methodology. Building inspection following this standard aims to assess the technical conditions, use, operation, maintenance and functionality of a building. It was observed in the results that in some cases there was an increase in the state of degradation in the materials present in some pathologies, with variations mainly in the amount of moisture and mold stains verified.
\end{abstract}

Keywords: Pathology of construction, civil construction, educational institution.

\section{INTRODUÇÃO}

Com a evolução dos aspectos econômicos e tecnológicos, o ser humano aumenta o seu poder de transformação da natureza, e é cada vez mais exigente quanto ao seu abrigo. Essas exigências são, principalmente, relativas aos aspectos de segurança, habitabilidade e sustentabilidade (JESUS et al., 2018).

Algumas dessas moradias e abrigos, em todas as épocas desde os primórdios da civilização, não tem apresentado desempenho satisfatório em relação às exigências dos usuários. $\mathrm{O}$ crescimento muito acelerado da construção civil provoca a necessidade de inovações, que contribuem com a aceitação de riscos, além de demandarem maior conhecimento acerca dos materiais e das estruturas. De qualquer maneira, a preocupação com os problemas que geram incômodos nos usuários é muito antiga e, pode-se dizer que, surgiu com o próprio ato de construir (LICHTEINSTEIN, 1985).

A abordagem dessa preocupação de modo sistemático é recente, surgindo com a aplicação na Engenharia Civil do conceito de desempenho, onde o edifício e seus componentes são produtos 
cuja finalidade é atender às necessidades dos usuários (segurança, habitabilidade, durabilidade, e sustentabilidade) (SOUZA et al, 1995).

Seja nas edificações ou em obras de infraestrutura, entende-se por manifestações patológicas das construções, a ciência que estuda as causas, os mecanismos de ocorrência, as manifestações e as consequências das falhas na construção civil ou nas situações em que a edificação não apresenta um mínimo exigido pelo usuário.

De modo geral, esses sintomas patológicos não têm sua origem concentrada em fatores isolados, mas sofrem influência de um conjunto de variáveis, classificadas de acordo com o processo de cada material ou sistema, com os sintomas, com a causa que gerou o problema e, ainda, com a etapa do processo produtivo em que ocorrem.

As manifestações patológicas são também responsáveis por uma parcela importante da manutenção, e grande parte das intervenções de manutenção nas edificações poderia ser evitada se houvesse um melhor detalhamento do projeto e a escolha mais apropriada dos materiais e dos componentes da construção (DUNSTON e WILLIAMSON, 1999).

Os projetos de execução da manutenção preventiva são incipientes e tornam-se uma prática usual nas instituições públicas, a chamada "manutenção não-planejada", na qual se está sempre corrigindo um problema de natureza imprevisível, mas que poderia ter sido evitado se fossem executados procedimentos de prevenção (COSTA JUNIOR, 2001). De acordo com Souza (2000) esse problema atinge um número considerável de instituições públicas no Brasil.

Sob o impacto de uma crise financeira que se abateu sobre o país, o Brasil se encontra num momento de reduzir despesas onde for possível, para que não faltem recursos em setores essenciais. Trata-se de uma nova realidade para gestores que ainda não se adequaram à urgencia de se tomar todos os cuidados necessários com o dinheiro público (SOUZA FILHO, 2017; BARBOSA FILHO, 2017).

A fase de produção de um edifício no Brasil é razoavelmente bem conhecida. Mas ao se deixar de lado pesquisas voltadas para as fases de uso, operação e manutenção, passa-se a ter uma visão incompleta do processo de construção, acarretando em redução de vida útil dos ambientes construídos. Repetições de falhas, nos projetos futuros de edifícios semelhantes, ocorrem devido à falta de retroalimentação e análise dos fatos ocorridos em ambientes já em uso. Para que esse círculo seja rompido é preciso alimentar esse ciclo com informações da fase de ocupação, tanto do ponto de vista técnico quanto do ponto de vista dos usuários (ORNSTEIN, 1992).

Em se tratando de edificações escolares, as manifestações patológicas são bastante comuns, uma vez que na maioria das situações tem-se: projetos padronizados, ocorrendo muitas vezes a falta de detalhamentos técnicos, bem como a inexistência de projetos complementares bem definidos (hidráulico, por exemplo); a especificação dos materiais é feita em função do preço; os controles realizados na fase de execução são em grande parte deficientes e/ou inadequados e, em algunas dessas obras, esse controle inexiste. Um outro fator agravante da degradação das edificações escolares é a falta de sensibilização dos usuarios com a conservação, gerando falhas na fase de operação (ARAÚJO, 2004; SCHARDONG e PAGNUSSAT, 2011).

A análise de manifestações patológicas em edificações escolares se torna difícil com o passar do tempo, devido à pouca manutenção e ao uso intensivo das escolas, gerando um alto nivel de degradação de seus elementos, com o surgimento de anomalías cada vez mais complexas (AZZALIN, 2005).

As manifestações patológicas presentes nos edifícios da Universidade Federal do Espírito Santo (UFES), oriundas em muitos casos da ausência dos devidos cuidados nas fases de produção e uso, trazem prejuízo ao Governo Federal, que muitas vezes deixa de investir em ensino e pesquisa para realizar reparos e reposições de componentes nestas edificações. Não é desnecessário lembrar que os cortes orçamentários restringem os recursos destinados às atividades de manutenção. 


\section{PROCEDIMENTO}

O estudo de caso envolveu pesquisa bibliográfica e descritiva. Após a revisão da bibliografia e delineamento da metodologia foi realizado o estudo de caso, onde se definiu e selecionou-se os edifícios da UFES, campus Alaor de Queiroz Araújo (campus de Goiabeiras), como universo amostral, com base em critérios descritos nessa metodologia.

Em relação à análise dos dados foram apresentadas as distribuições das edificações avaliadas por idade, construtora, tipo de edifício e centros a que pertencem, sendo essas algumas das variáveis consideradas.

No trabalho desenvolvido por Costa Junior (2001) foi utilizada a metodologia de avaliação pós ocupação (APO), para a observação e o registro das manifestações patológicas existentes nas edificações da UFES.

Os resultados obtidos na pesquisa de Costa Junior (2001), forneceram informações sobre os dados históricos da construção dos edifícios do campus de Goiabeiras, permitindo a caracterização do universo pesquisado. Tais dados dizem respeito às características gerais das edificações no ano de sua construção, ao tipo de edifício, ao centro a que pertencem, à sua área construída e à empresa construtora.

O agrupamento e a escolha dos edifícios selecionados por Costa Junior (2001), para a observação e o registro das manifestações patológicas, basearam-se nos seguintes critérios:

- Representatividade, tentando-se selecionar um ou mais edifícios que representassem cada centro da universidade;

- Características construtivas, como edifícios de concreto aparente, de um, dois ou três pavimentos; de localização dentro do campus da universidade, seleccionando-se edifícios de diferentes localizações, tais como, próximo ao lago, à rua principal, à área de manguezal, entre outros;

- Informações existentes, registros quanto às características gerais: ano de construção, tipo de edificação, centro a que pertencem e as empresas construtoras;

- Quantidade - o campus alvo da pesquisa (Campus Alaor Queiroz Araújo) apresenta 126 edificações, das quais 73 são cabines, guaritas, quadras de esportes, bancos, áreas de lazer, entre outros; e 53 são edifícios de sala de professores, salas de aula, administração, laboratórios e centros de vivência, que foi o grupo de edifícios pré-selecionado para a avaliação. Porém, destes 53 edifícios selecionou-se $40 \%$ deles foram selecionados como amostra representativa, resultando nos 21 prédios avaliados nesse trabalho.

O levantamento das patologias nas edificações foi realizado por meio de registro fotográfico, quantificado e categorizado, conforme observado no Quadro 1, segundo a metodologia de Costa Junior (2001).

Quadro 1 - Levantamento das manifestações patológicas encontradas de acordo com o sistema.

\begin{tabular}{|c|c|}
\hline Sistema ou subsistema & Sintomalogia patológica detectada \\
\hline $\begin{array}{c}\text { instalações hidrossanitárias } \\
\text { e impermeabilização }\end{array}$ & $\begin{array}{c}\text { infiltração, problemas nas louças sanitárias, manchas de } \\
\text { umidade e bolor }\end{array}$ \\
\hline Vedações horizontais & fissuras e manchas de umidade e bolor \\
\hline Vedações verticais & $\begin{array}{c}\text { fissuras, destacamento do revestimento, zonas estufadas, } \\
\text { manchas de umidade e bolor, desprendimento de placa } \\
\text { cerâmica, descolamento de revestimento, rejuntes e piso, e } \\
\text { eflorescência }\end{array}$ \\
\hline Esquadrias & $\begin{array}{c}\text { esquadrias empenadas, vidros danificados, manchas de umidade } \\
\text { e bolor, fissuras, infiltração, corrosão }\end{array}$ \\
\hline Estruturas & $\begin{array}{c}\text { Fisuras, manchas de umidade e bolor, infiltração, corrosão da } \\
\text { armadura, niños de concretagem, eflorescencias e fungos }\end{array}$ \\
\hline
\end{tabular}


Definidas essas diretrizes, segundo Costa Junior (2001), a pesquisa de campo foi realizada segundo as instruções da norma de inspeção predial nacional do Instituto Brasileiro de Avaliações e Perícias de Engenharia (IBAPE, 2012). Esta norma apresenta os conceitos e os critérios para a realização da Inspeção Predial.

De acordo com a metodologia de inspeção descrita na norma de inspeção predial nacional do Ibape, o objetivo das imagens é identificar as manifestações patológicas encontradas, classificar o objeto da inspeção, determinar a sua localização, assim como a data, a sua descrição técnica, a tipologia e o padrão construtivo, a utilização e a ocupação da edificação, assim como a sua idade.

De modo a se verificar a evolução da degradação das manifestações na Universidade ao longo do tempo (20 anos), desde a pesquisa realizada por Costa Junior (2001)), contou-se com a ajuda de informações obtidas por meio da revisão bibliográfica, consultas aos projetos disponíveis na Superintendência de Infraestrutura (SI) da UFES, além de questionamentos junto à equipe técnica responsável por esse setor.

Os resultados desse levantamento foram comparados com aqueles encontrados por Costa Junior (2001), observando-se as principais mudanças nas manifestações, em geral, função do tempo decorrido.

\section{RESULTADOS}

\subsection{Principais manifestações patológicas encontradas nos edifícios da universidade}

Na Figura 1 estão descritas as manifestações patológicas encontradas em estruturas inspecionadas durante o levantamento de campo. Observa-se que $86 \%$ dos edifícios avaliados apresentam manchas de umidade e bolor e apenas 14\% dos edifícios apresentam eflorescência.

Os dados da Figura 1 foram mensurados por meio da incidência de manifestação patológica (fissuras, infiltração, etc.), em estruturas das edificações pesquisadas. Assim, se uma manifestação patológica foi identificada durante a inspeção no edifício, ela passa a ser considerada como existente naquela edificação. Essa mensuração foi realizada, também, nos outros subsistemas estudados (instalações hidrossanitárias, vedações, etc.).

Vale ressaltar que a tipologia construtiva observada nessas edificações é de estructura de concreto armado, com fck variando de 15 a $20 \mathrm{MPa}$, sem especificação da relação de água/cimento.

- Manchas de umidade e bolor
- Fissuras
- Infiltração
- Corrosão de armaduras
ninhos de concretagem
Eflorescência
- Fungos

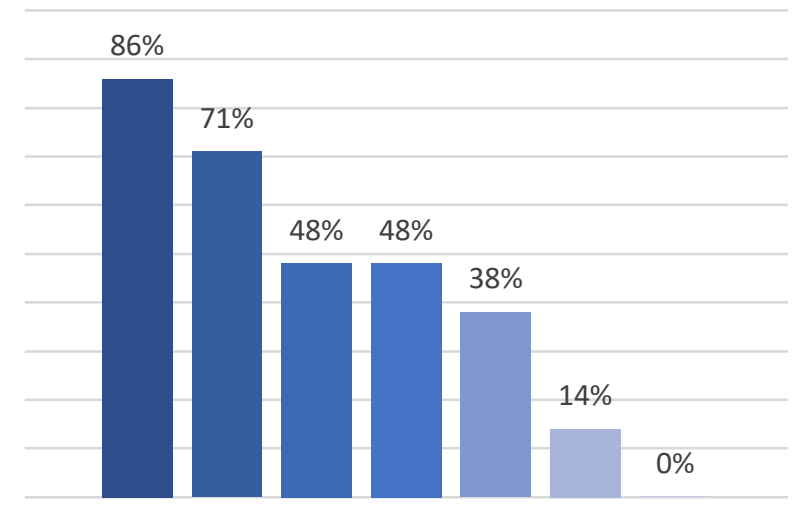

Figura 1: Frequência das manifestações patológicas em estruturas das edificações da UFES. As manifestações patológicas observadas nesta avaliação não diferenciam muito daqueles problemas encontrados na revisão bibliográfica, onde se observa que entre as principais sintomatologias destacam-se as fissuras, as eflorescências, as manchas, o descolamento da pintura, o mofo e o bolor, as infiltrações em esquadrias, a armadura aparente, os ninhos de concretagem, a 
segregação e a desagregação do concreto e as flechas excessivas (OLIVEIRA, 2000; GRILO e CALMON, 2000; ANDRADE e DAL MOLIN, 1997; APPLETON, 1994; HELENE, 1992).

Comparando os resultados com aqueles obtidos por Costa Junior (2001), observa-se constância na quantidade de fissuras (71\%), um acréscimo de 10\% nas infiltrações, elevando de 38\% para 48\%, assim como em ninhos de concretagem, antes $28 \%$, agora $38 \%$. Corrosão de armaduras evoluiu de $33 \%$ para $48 \%$, eflorescências tiveram uma redução de $28 \%$ para $14 \%$. Houve um aumento significativo nas manchas de umidade e bolor, que evoluíram de $57 \%$ para $86 \%$.

Observou-se, ainda, que muitas destas manifestações encontradas são interdependentes e correlacionadas, devido às múltiplas relações de causa e efeito que as caracterizam, como o fato de fissuras que podem, ao mesmo tempo, constituir uma das causas de infiltrações ou o início de um processo de corrosão das armaduras.

A Figura 2 apresenta a distribuição das manifestações patológicas relacionadas com as instalações hidrossanitárias. Observa-se que $20 \%$ dos edifícios avaliados apresentam infiltrações, que são muitas vezes seguidas de vazamentos.

Houve constância nos números de infiltração comparando-se com o estudo de Costa Junior (2001) (26,15\%), aumento no número de manchas de umidade e bolor, subindo de $4,8 \%$ para $20 \%$, e relativa constância no número de problemas nas louças sanitárias, com 14,3\% em 2001 e 13\% em 2018.

As análises feitas por Costa Junior (2001), mostraram que não há compatibilização entre os projetos de hidráulica/impermeabilização. Fato esse que gera improvisos durante a execução e tem reflexos negativos no desempenho dos edifícios.

A ausência de compatibilização de projetos é ainda hoje observada em instituições públicas e privadas no Brasil. Nem sempre existem coordenadores e há dificuldade de entendimento do que fazer em termos de coordenação e compatibilização, e de como fazer. Os projetos são elaborados por profissionais diferentes, que não se preocupam com a busca de continuidade dos projetos, o que poderia ser diminuído com a utilização de softwares com plataforma BIM (CRUZ, 2011).

Com o objetivo de reunir todas as informações de uma construção, de forma integrada e organizada, foi estabelecido pelo Decreto ${ }^{\circ}$ 10.306, de 2 de abril de 2020, a utilização do Building Information Modelling (BIM ou Modelagem de Informações da Construção) na execução direta ou indireta de obras e serviços de engenharia, realizada pelos órgãos e pelas entidades da administração pública.

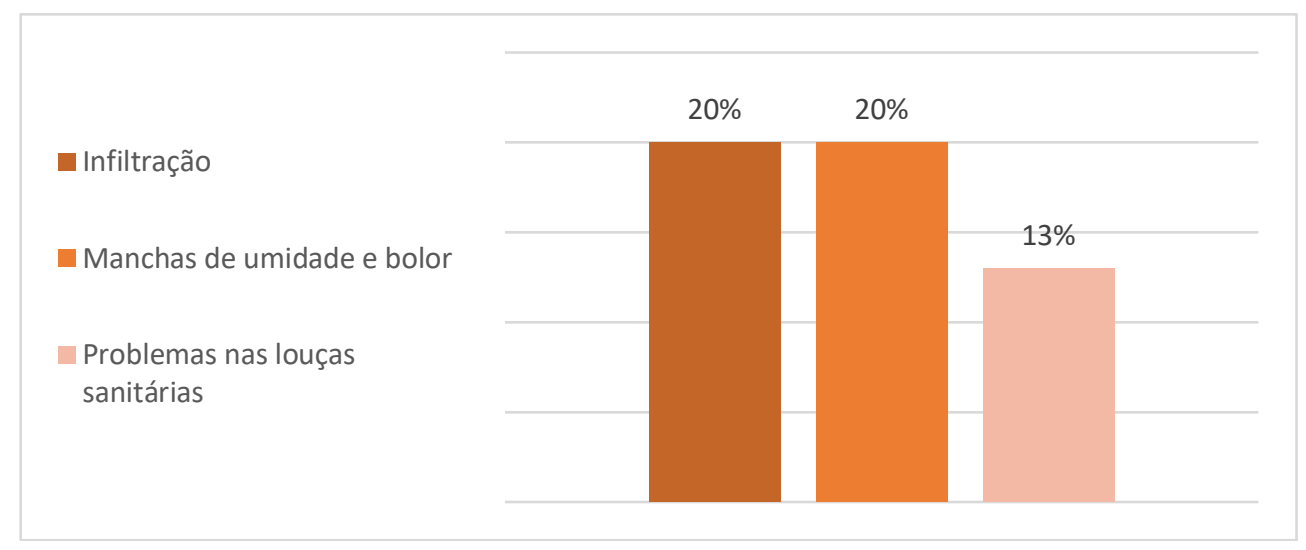

Figura 2: Manifestações patológicas relacionadas com instalações hidrossanitárias e impermeabilização nas edificações da UFES.

Após consulta a projetos disponíveis na Superintendência de Infraestrutura, verificou-se que as edificações entregues após o ano de 2001 na UFES não utilizaram nenhuma ferramenta de compatibilização de projetos. 
Para as vedações horizontais, assim como nos itens anteriores, as manchas de umidade e bolor obtiveram aumento, sendo observadas em 59\% das edificações avaliadas (no trabalho de Costa Junior (2001) o valor é de 38\%), enquanto as fissuras mantiveram-se constantes no patamar de $47 \%$, como se pode observar na Figura 3.

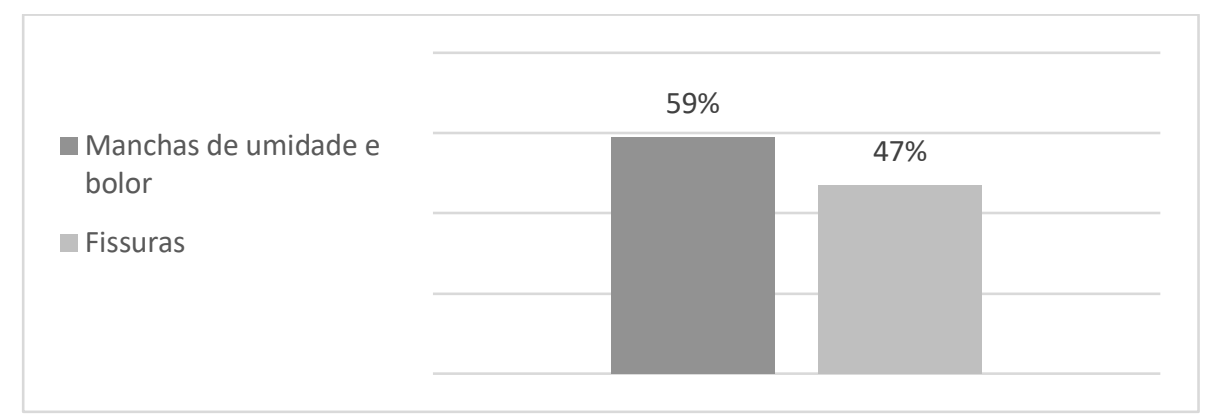

Figura 3: Manifestações patológicas em vedações horizontais nas edificações da UFES.

Para as manifestações patológicas observadas na figura 4, no subsistema revestimentos e vedações verticais, as fissuras se mostraram em $48 \%$ dos edifícios avaliados, tendo uma redução significativa em relação ao estudo de Costa Junior (2001), cujo valor foi de $100 \%$.

Em termos comparativos, observa-se na figura 5 as porcentagens de manifestações patológicas em revestimentos e vedações verticais nas edificações da UFES inspecionados nessa pesquisa, em comparação com os resultados obtidos por Costa Junior (2001). Com exceção das manchas de umidade e bolor, houve uma redução nas ocorrências das patologías encontradas em vedações verticais.

Observa-se, ainda, variação no número de fissuras encontradas nos revestimentos e vedações verticais. Esclarece-se que esse número não deve ser interpretado sozinho. Trata-se de um dado que serve de complemento para o entendimento de uma idéia que se quer apresentar, uma vez que as fissuras variam desde pequenas aberturas no revestimento das vedações até aberturas na ordem de centímetros que atravessam blocos de vedação.
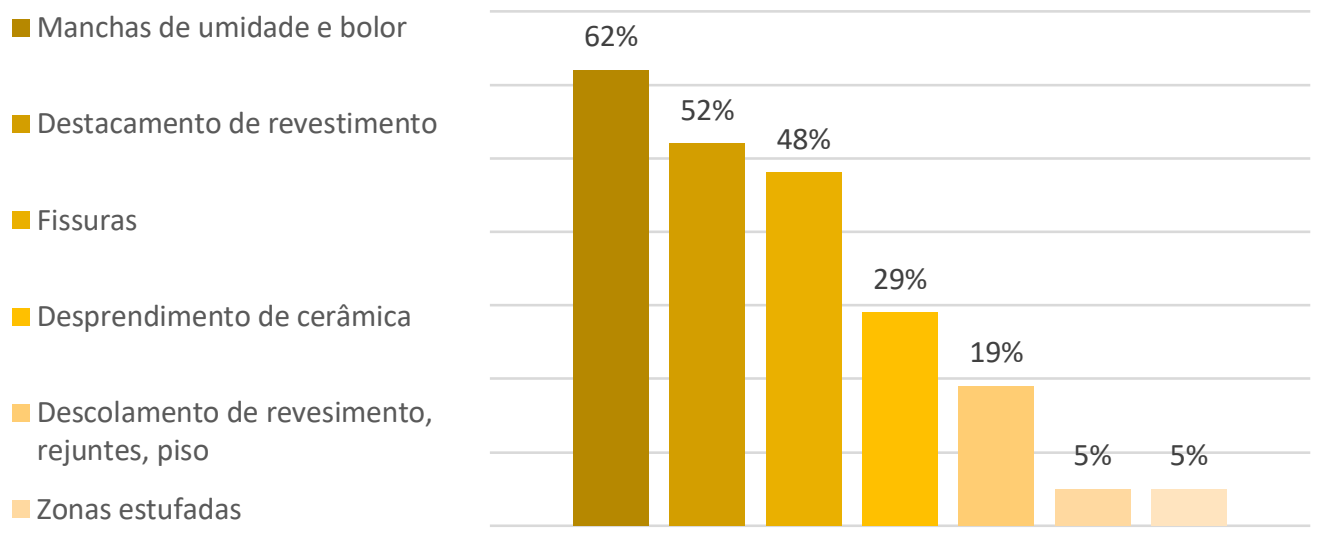

Figura 4: Manifestações patológicas em revestimentos e vedações verticais. 


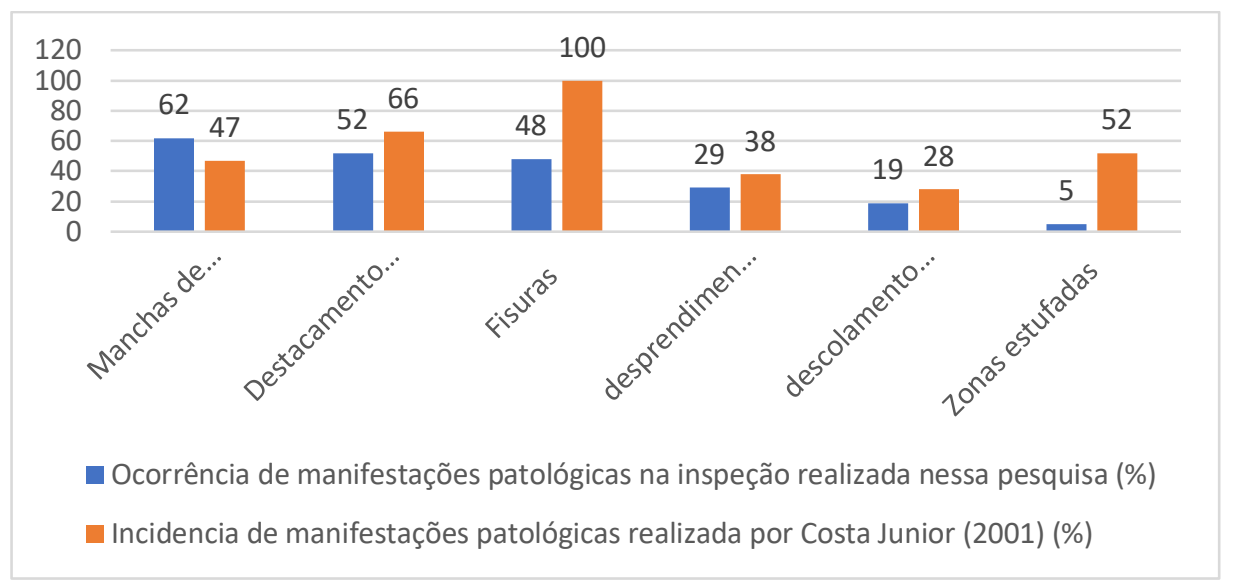

Figura 5: Comparação de manifestações patológicas desse trabalho com o de Costa Junior (2001).

O gráfico da Figura 6 apresenta os problemas encontrados nas esquadrias. Em 45\% dos edifícios avaliados foram encontradas esquadrias empenadas, contra 28\% em 2001. Corrosão também foi um item que obteve aumento significativo, com $45 \%$ comparados a $4 \%$ em 2001 . Esses problemas costumam vir acompanhados de apodrecimento e infiltração.

Outro problema muito comum, observado em 23\% das edificações avaliadas por Costa Junior (2001), foram vidros danificados que apresentavam, principalmente, fissuras, que podem ter sido resultado de vandalismo, de problemas de expansão térmica, ou por sombreamento excessivo de suas bordas, que causa uma diferença de temperatura entre a região central e as bordas do vidro (THOMAZ, 1989). Nessa pesquisa tais problemas foram observados em $15 \%$ dos edifícios avaliados.

A análise feita é que na maioria dos casos houve degradação natural dos elementos da esquadria, dada a idade avançada das edificações, não havendo reposição dos constituintes.

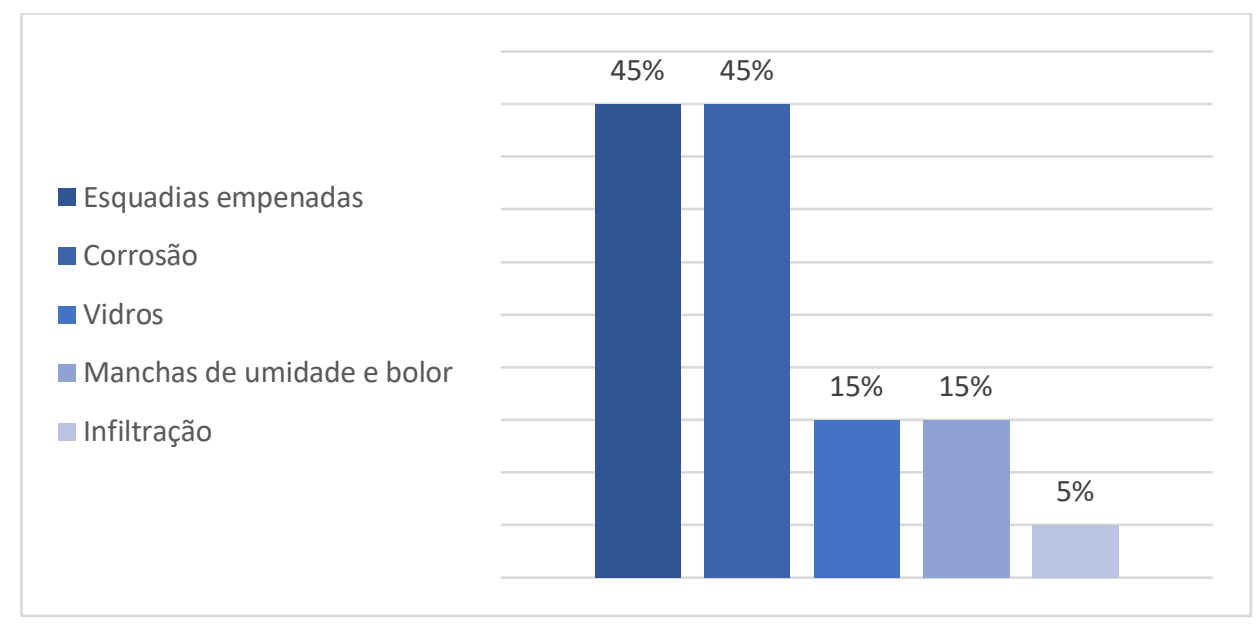

Figura 6: Defeitos em esquadrias nas edificações da UFES. Fonte: Autor

As fotos, a seguir, apresentam algumas das principais manifestações encontradas nas edificações da UFES durante o levantamento realizado nessa pesquisa. Como manchas de umidade e bolor, tem-se o exemplo da Figura 7a, onde a vedação horizontal foi consumida pela umidade, no banheiro do prédio da Reitoria. A Figura $7 \mathrm{~b}$ mostra o mesmo problema, mas desta vez no pavimento térreo do Restaurante Universitário. De forma menos acentuada, mas também presente, no banheiro de um laboratório do CT V (Figura 7c) e no revestimento externo de uma boa quantidade de edifícios, como o caso da Figura 7d, no edifício CT I. 

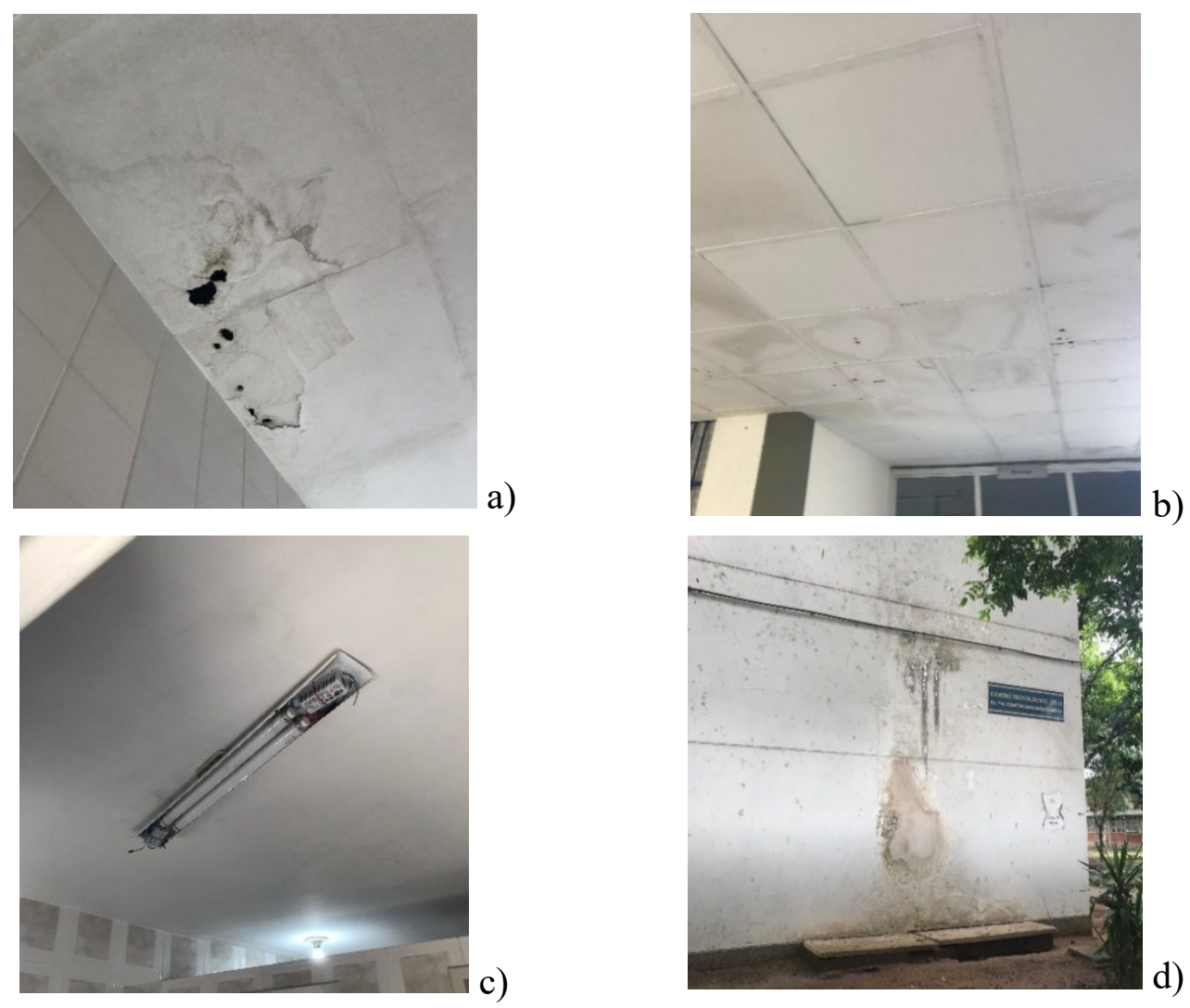

Figura 7 - Principais manifestações patológicas (manchas de umidade e bolor), em 2021.

Fonte: Autores.

As manchas de umidade e bolor estão entre as manifestações mais comuns em edificações, sendo que há uma série de mecanismos associados a estas manifestações patológicas (BAUER, 1997). Umidades são causadas principalmente por vazamentos em tubulações, decorrentes de má execução ou falhas no projeto, e ainda por falhas nos revestimentos de vedação, seja por uso incorreto de pinturas impermeabilizantes ou até mesmo falhas na produção da argamassa de revestimento (FIBERSALS, 2018).

Muitas são as causas dessas manifestações, podendo-se destacar nessa pesquisa:

- Bolor pode ser ocasionado também por argamassas de assentamento magras e porosas (CARASEK, 2007);

- Pode-se atribuir este problema também à ausência ou deficiência de impermeabilização.

Para as fissuras, foram encontradas: fissura em diagonal acompanhando os blocos de vedação no edifício CEMUNI III (Figura 8a); fissura horizontal ligando os vãos da porta e janela (Figura 8b) no prédio da Reitoria; fissura vertical próximo ao encontro de vedações no auditório do CCJE ED III (Figura 8c); e fissura vertical na vedação em madeira no prédio IC III (Figura 8d).

Entre as causas dos principais tipos de fissuras, pode-se destacar: problemas com a argamassa de vedação, com a argamassa de assentamento, problemas de amarração da parede com elementos estruturais, retração das lajes, dilatações térmicas, recalques de fundações, ausência de vergas e contravergas, retração da alvenaria, entre outros (THOMAZ, 1989; COSTA, 1993; CASADO, 1997; THOMAZ, 1998; ROCHA, 1998; EBANATAW, 2001). 

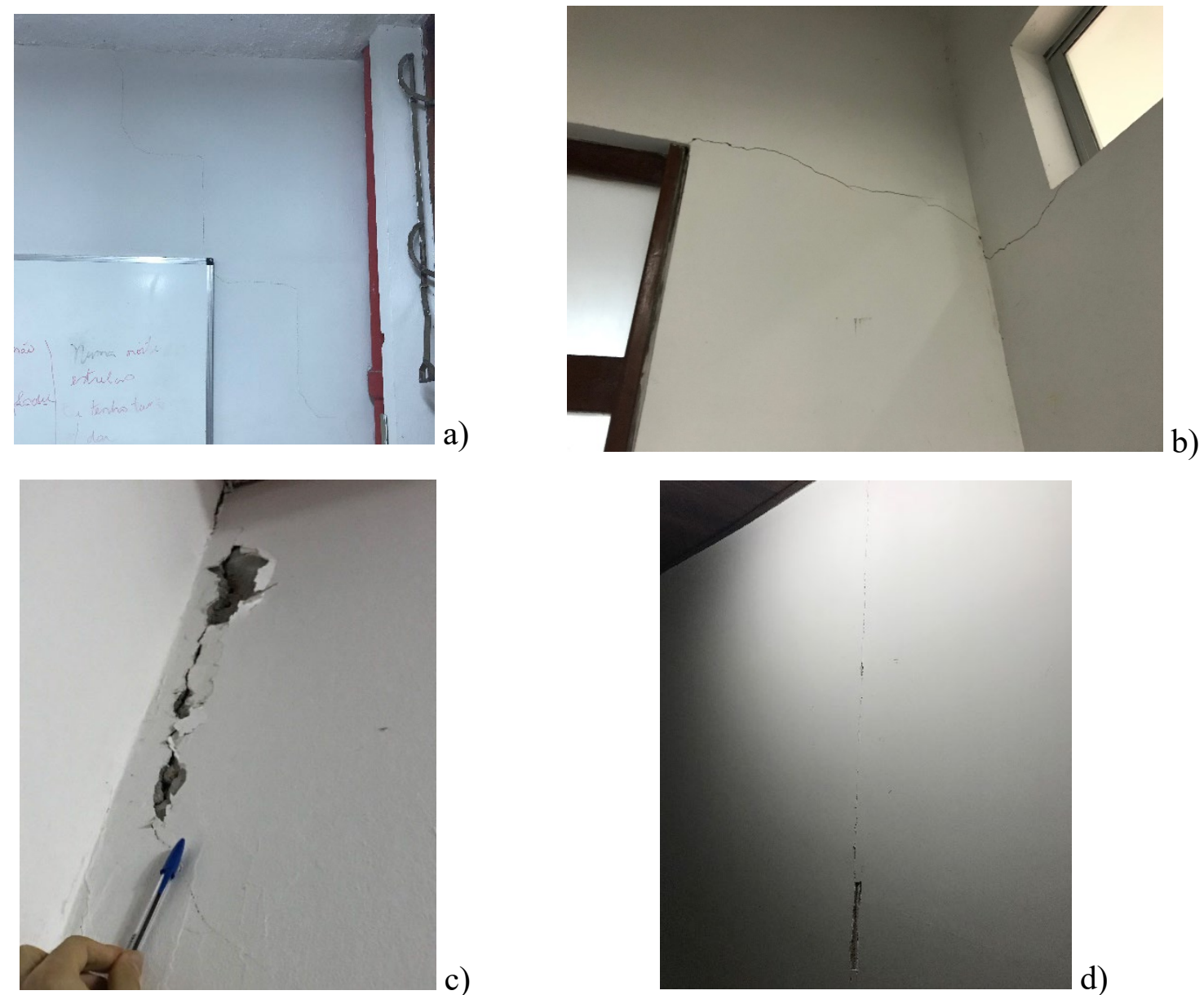

Figura 8 - Principais manifestações patológicas nas edificações da UFES (fissuras), em 2021.

Fonte: Autores.

Dentre as causas prováveis, destacam-se:

- Dimensões do painel de alvenaria, dimensões da abertura, posição que a abertura ocupa no painel e dimensões e rigidez das vergas e contravergas (THOMAZ, 1989).

- Observou-se, por meio do caderno de especificações da UFES, a indicação da colocação de vergas de concreto armado, convenientemente dimensionadas e com um mínimo de $20 \mathrm{~cm}$ de apoio para cada um dos lados. Este apoio pode ser insuficiente, pois concentra cargas excessivas sobre a alvenaria. Em janelas observou-se também este problema, que pode ter ocorrido devido à ausência de contravergas nos peitoris, (BAUER, 1997).

- Baixa deformabilidade da ligação entre a alvenaria e os elementos estruturais, que só deve acontecer após 15 a 30 dias da execução da alvenaria (BAUER, 1997).

Observa-se a incidência de infiltração no revestimento de vedação horizontal do CT I (Figura 9a), no revestimento externo dessa mesma edificação (Figura 9b), parcialmente tratada na Biblioteca Central (Figura 9c), na vedação horizontal do banheiro masculino do prédio da Botânica (Figura 9d).

Dentre as causas prováveis, destacam-se:

- Problemas de infiltração, através de lajes de cobertura, ocorrem principalmente quando não é feita a impermeabilização ou quando ela é deficiente (VERÇOSA, 1989; LYALL, 1992).

- Vazamentos através de fissuras ou eletrodutos. 

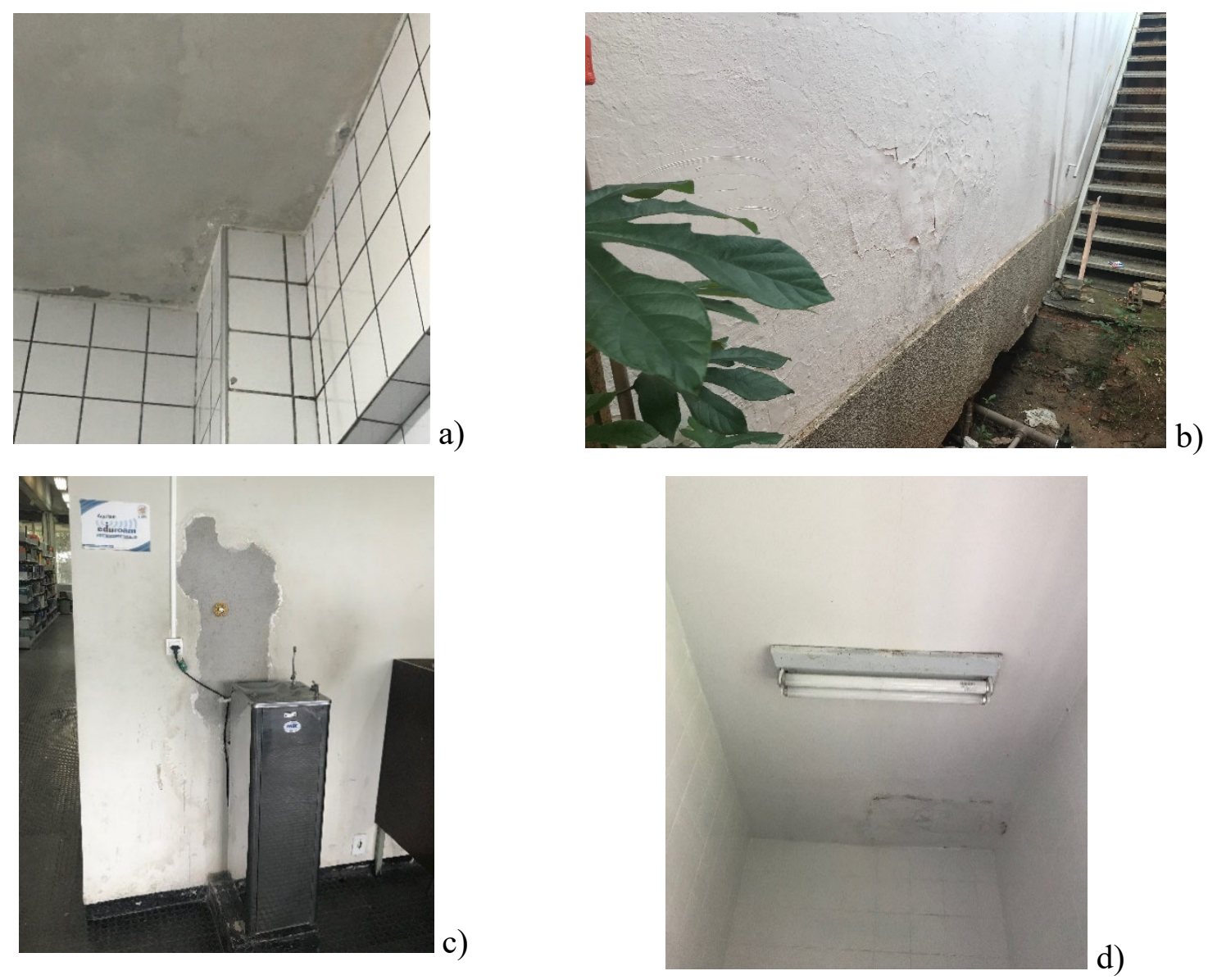

Figura 9 - Principais manifestações patológicas nas edificações da UFES (infiltração), em 2021.

Fonte: Autores.

Quanto à corrosão de armadura, entre os casos encontrados pode-se destacar: pilar interno do prédio da Reitoria (Figura 10a), Pilar externo do NTI (Figura 10b).

É interessante notar que, nesses casos, pode-se perceber uma perda no cobrimento da armadura, assim como variações do grau de corrosão da armadura, o que ocasiona perdas na resistência original desses elementos (BRANCO, PAULO e GARRIDO, 2013).
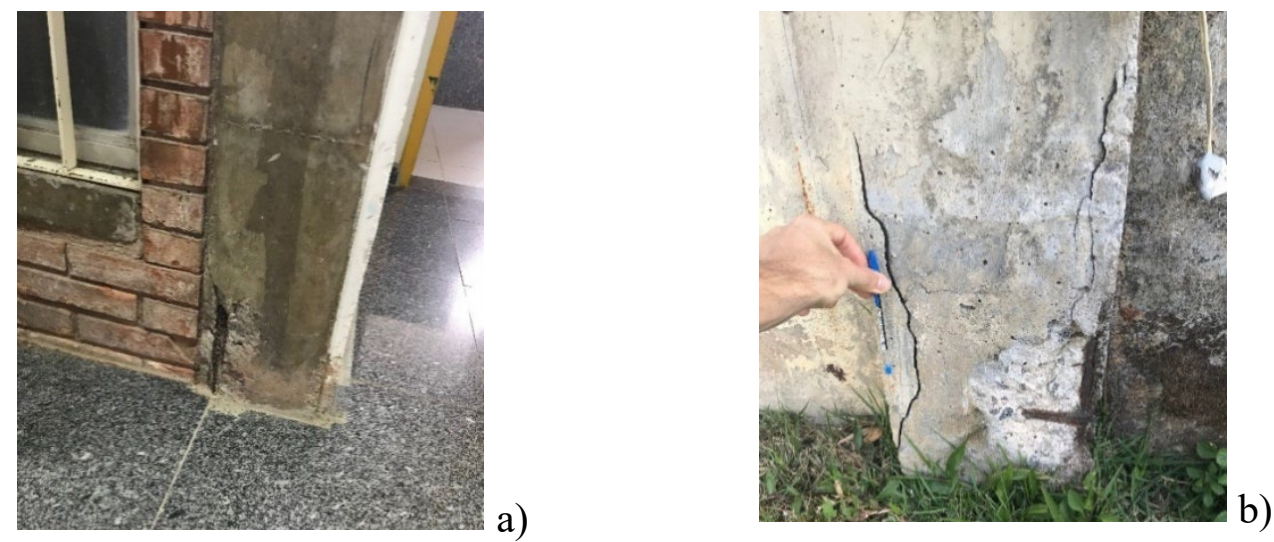

Figura 10 - Principais manifestações patológicas nas edificações da UFES (corrosão da armadura), em 2021.

Fonte: Autores. 


\subsection{Comparação e evolução das manifestações patológicas}

Em uma análise mais detalhada pode-se observar o que provocou o surgimento e a propagação de algumas manifestações patológicas, desde o estudo de Costa Junior (2001) até a data da realização deste trabalho.

Começando pela fissura observada por Costa Junior (2001) na base de pilar da Escola de $1^{\circ} \mathrm{Grau,}$ com manchas de umidade e bolor e proliferação de fungos (Figura 11a). Percebeu-se que nas imediações do pilar não havia nenhuma fissura ou mancha de umidade, o que pode significar que os acréscimos de tensão, que provocaram fissuras na base, foram resistidos sem danos ao elemento estrutural.

Um retorno ao local encontrou situação semelhante, à encontrada em 2001, na maioria dos pilares da edificação (Figura 11b), sendo que um desses pilares estava com aspecto de deterioração mais avançado que os demais (Figura 11c).

É provável terem sido essas fissuras causadas por movimentações do solo ao longo do tempo decorrido, desde a entrega da edificação, sendo possível que a falta do cobrimento da armadura, e o contato com água (Figura 11d) tenha ocasionado ainda mais degradação no último pilar (Figura 11c). A realização de novas análises, mais detalhadas poderá determinar com um grau maior de certeza as suas causas.

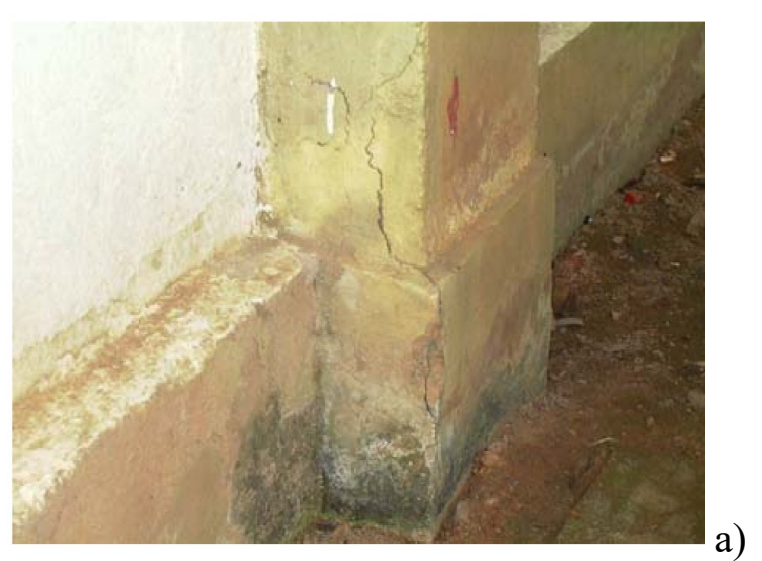

Costa Junior (2001)

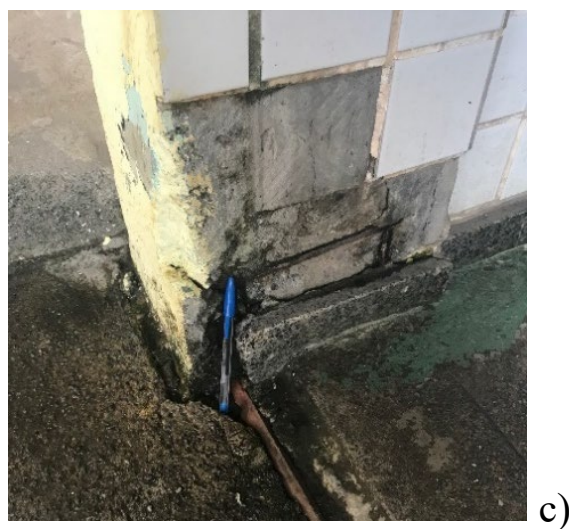

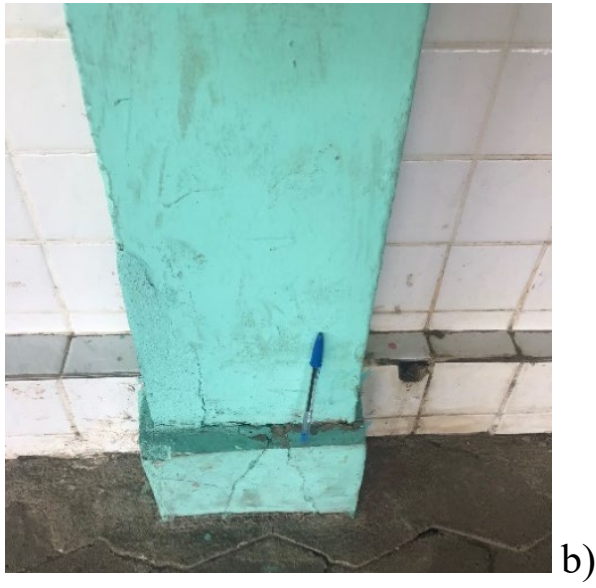

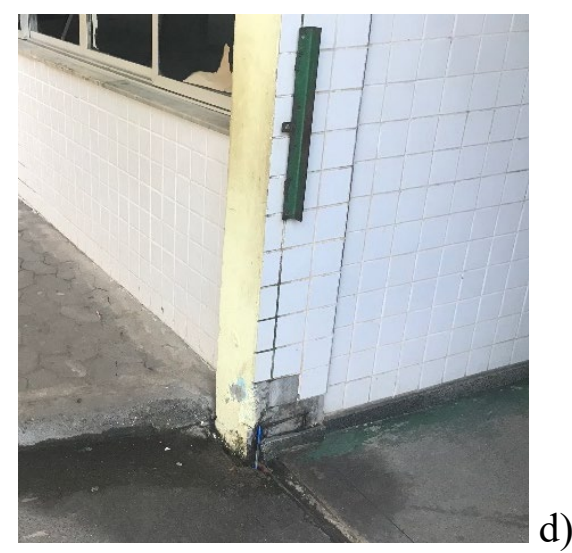

Figura 11 - Análise de 2001 (Figura a) e atual das bases de pilar na escola de $1^{\circ}$ grau (Figura b, c, d), em 2021.

Fonte: Autores. 
Em se tratando de uma edificação onde ocorrem atividades escolares de crianças, a possibilidade de ocorrência de falhas deveria ser mínima. O ideal é que seja feita uma avaliação detalhada com os projetos arquitetônico e estrutural, em mãos, afim de se determinar a resistência residual de cada elemento da estrutura, além de ensaios na armadura, de modo a calcular com precisão qual será o comportamento da estrutura ao longo do tempo.

As fissuras em diagonal observadas por Costa Junior (2001) no Centro de Vivência (figuras 12a) se iniciam no canto da abertura da porta e provocaram desprendimento de cerâmica. A fissura atravessa a alvenaria. Foram observadas também em outras áreas do edifício.

Nota-se uma tentativa de contornar a situação pela colação de placas de cerâmica onde haviam ocorrido as falhas (Figura 12b), mas é provável que a lenta, porém, constante movimentação de separação na fissura provocou o reaparecimento da marca, em toda a parede.
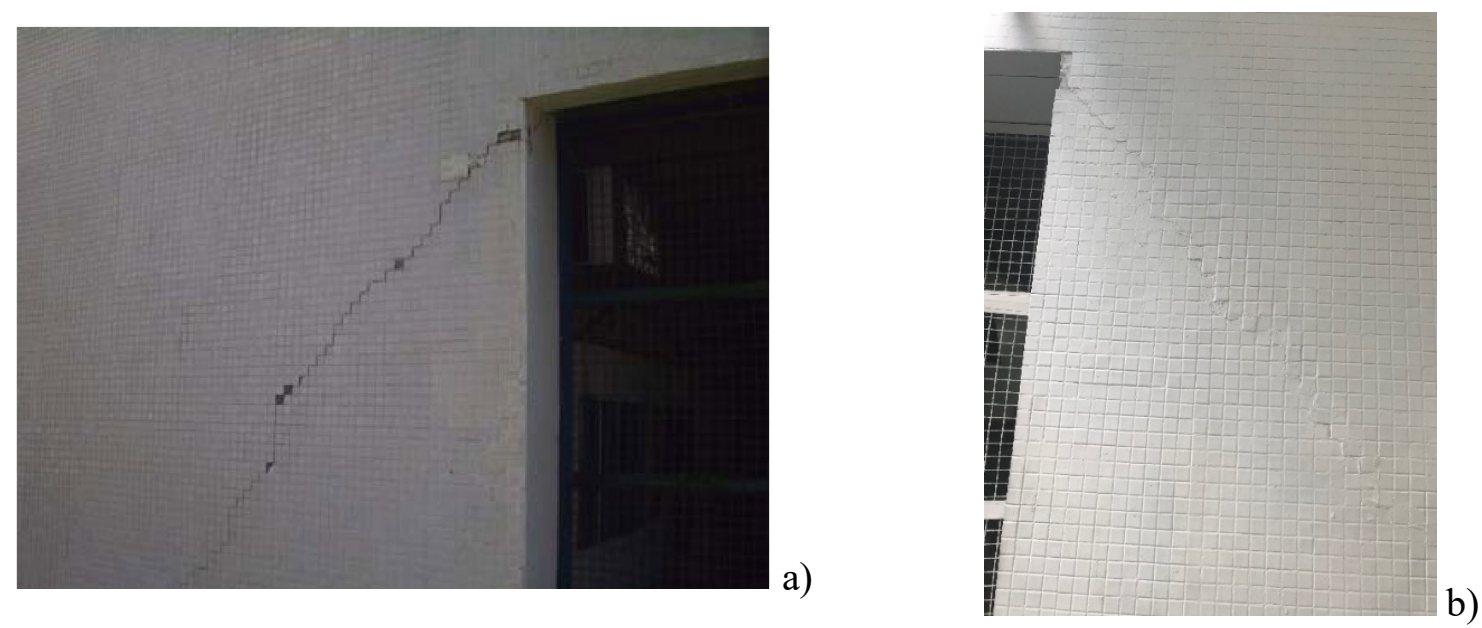

Figura 12 - Análise de 2001 (Figura a) e atual (Figura b, em 2021) das fissuras no centro de vivencias.

Fonte: Autores.

Entra as causas de fissuras inclinadas nas paredes estão: recalques de fundações, ausência de vergas e contra vergas, concentração de tensões (sobrecargas) (THOMAZ, 1989; COSTA, 1993; CASADO, 1997; THOMAZ, 1998; ROCHA, 1998; EBANATAW, 2001). Pelo fato das fissuras se encontrarem em várias partes da parede, não somente próximo aos vãos das portas, é provável que exista algum tipo de tensão não previsto em projeto, seja por movimentação da estrutura de fundação ou não.

A figura 13a mostra um problema de infiltração, observado por Costa Junior (2001), onde ocorreu a lixiviação de produtos de hidratação do cimento, como hidróxido de cálcio, e a formação de estalactites, como o carbonato de cálcio.

A literatura recomenda a remoção desse material com jato de água. Verifica-se que houve um trabalho de remoção desse material, mas, não foi tratada a fonte da presença de umidade, e assim, o surgimento do material ocorreu novamente gerando incômodos estéticos, principalmente, à estrutura. (Figuras 13b). 

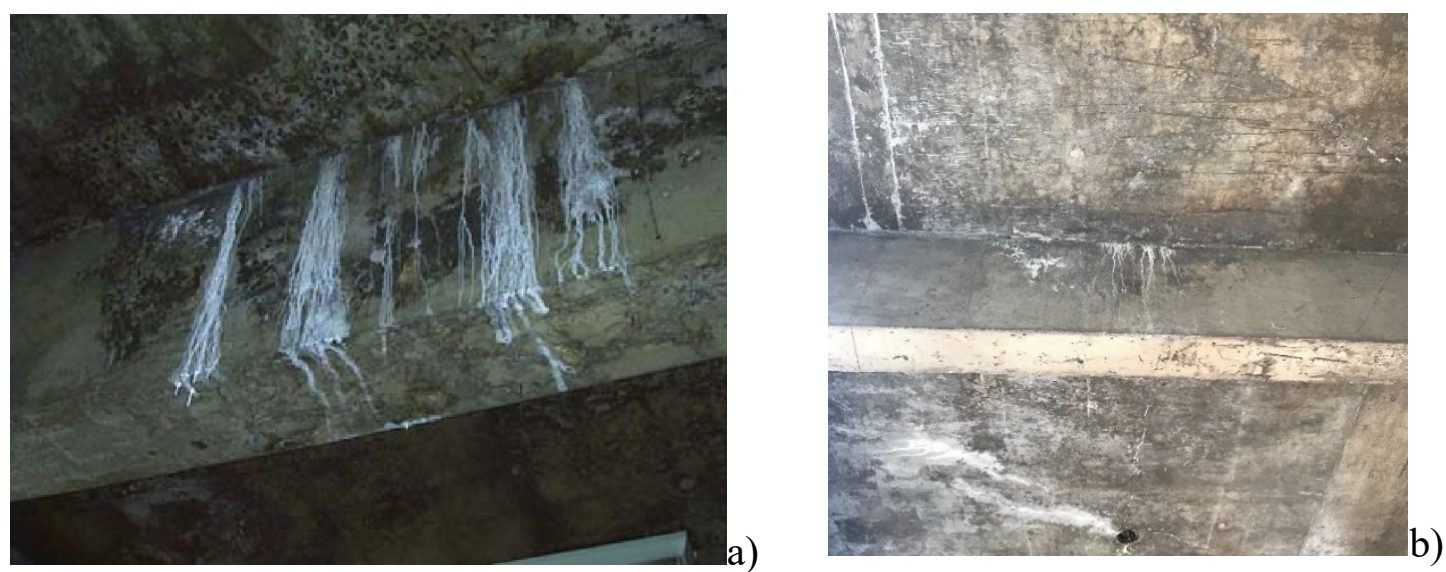

Figura 13 - Análise de 2001(Figura a) e atual (Figura b, em 2021) da incidência de eflorescência na Reitoria.

Fonte: Autores.

\section{CONCLUSÕES}

Dentre as diversas manifestações patológicas observadas nas edificações da Universidade, algumas representam maior risco de provocarem paralisações ou danos contra a saúde ou a segurança dos usuários. São aquelas ligadas à estrutura das edificações, como as fissuras em pilares com corrosão da armadura (Escola de $1^{\circ}$ Grau, CT I, NTI, Restaurante Universitário).

Esses pilares fazem parte de estruturas que não possuem mais que uma laje, mas, apesar das baixas cargas quando comparadas a estruturas de múltiplos pavimentos, recomenda-se que sejam feitas inspeções detalhadas afim de se determinar o valor residual de resistência dos elementos, assim como um estudo de suas deteriorações, para que se possa determinar com precisão a vida útil residual da estrutura ou os reforços que se fazem necessários.

As demais manifestações patológicas encontradas na universidade podem ser caracterizadas como de médio e mínimo risco. Apesar disso, é recomendado que se faça a devida correção dos problemas, para que não venham a tornar-se de riscos maiores, e para que se evite o aparecimento de mofo e bolor, fontes de doenças.

Ao se analisar as manifestações patológicas encontradas nos edifícios estudados por Costa Junior (2001) e no atual trabalho, pode-se concluir que algumas dessas manifestações receberam algum tipo de tratamento, enquanto que outras aumentaram o nivel de degradação do seu estado.

A fissura horizontal encontrada em uma sala de aula do Centro de Línguas, por exemplo, recebeu o tratamento adequado. Também pode-se citar alguns casos de manchas de umidade e bolor que receberam o tratamento adequado, como no prédio da Reitoria.

O que ocorre, em uma quantidade considerável de casos, é que esses problemas receberam algum tipo de tratamento, mas, não tiveram acabamento na região tratada ou o tratamento nãofoi suficiente para controlar a fonte do surgimento, gerando novamente a ocorrência. Como exemplos podem ser citadas: a infiltração na parede da Biblioteca Central, a vedação horizontal do prédio do Núcleo de Línguas e a eflorescência no prédio da Reitoria.

Algumas manifestações mais dispendiosas ainda não receberam tratamento ou receberam tratamento inadequado, como é o caso da base de pilar da Escola de $1^{\circ}$ Grau e das fissuras no Centro de Vivência.

A Superintendência de Infraestrutura é o órgão responsável pelo planejamento, construção, conservação e manutenção das áreas físicas dos campus da UFES, assim como pela fiscalização dos contratos de obras e manutenção predial. Assim como o trabalho de Costa Junior, este também será enviado ao setor técnico responsável, para conhecimento e providências. 
A falta do controle da qualidade em todas as etapas do processo de construção, desde o planejamento, é o principal motivo do surgimento de manifestações patológicas nos edifícios da universidade (HELENE E SOUZA, 1988). Uma vez geradas as manifestações patológicas, os programas de controle e manutenção devem funcionar de maneira eficiente para que se possam distinguí-las e, de acordo com a sua classificação, dispensar-lhes o tratamento adequado, com o objetivo de se possuir edificações que satisfaçam aos usuários.

\section{AGRADECIMENTOS}

Os autores gostariam de agradecer a Universidade Federal do Espírito Santo pela autorização das vistorias realizadas, ou seja, pela disponilibização das edificações para a pesquisa, assim como acesso aos documentos pesquisados e profissionais da universidade entrevistados.

\section{REFERÊNCIAS}

ANDRADE, Jairo, DAL MOLIN, Denise. Influência da agressividade ambiental nas patologias em estruturas de concreto armado nas cidades de Porto Alegre (RS) e Recife (PE). In: Workshop - Durabilidade das construções. São Leopoldo - RS, 30 de junho a 01 de julho de 1997.

APPLETON, João. Patologia precoce dos edifícios. In: $2^{\text {a }}$ ENCORE - Encontro sobre conservação e reabilitação de edifícios. Comunicações, V. II. Lisboa, 27 de junho a 1 de julho, 1994. p. 823 834.

ARAÚJO, Letícia Santos Machado de. Avaliação durante operação dos sistemas prediais hidráulicos e sanitários em edificios escolares. Campinas, 2004. Dissertação (Mestrado) Faculdade de Engenharia Civil, Arquitetura e Urbanismo da Universidade Estadual de Campinas. AZZALIN, M. Building pathology database and maintenance approach in a welldefined context: Calabrian historical centers. 10th DBMC International Conference on Durability of Building Materials and Component. p 988-994. Lyon, France, 2005.

BARBOSA FILHO, Fernando de Holanda. A crise econômica de 2014/2017. Estud. av. [online]. 2017, vol.31, n.89 [citado 2021-03-15], pp.51-60.

BAUER, Roberto. Patologia em revestimento de argamassa inorgânica. II Simpósio Brasileiro de Tecnologia das argamassas Anais... Salvador-BA, 17 e 18 de abril de 1997, p. 321-331.

BRANCO, F.; PAULO, P.; GARRIDO, M. Vida Útil na construção civil. Boletim Técnico. Alconpat, 2013.

CARASEK, H. Argamassas. Materiais de Construção Civil e Princípios de Ciência e Engenharia de Materiais. ISAIA, G.C. (Organizador/Editor). São Paulo: IBRACON, 2007 p863-804.

CASADO, Alberto L. Sistemas de recuperação de fissuras da alvenaria de vedação: avaliação da capacidade de deformação. Dissertação de mestrado, São Paulo, 1997.

COSTA JUNIOR, M. Avaliação pós-ocupação e manutenção estratégica de escolas públicas. Dissertação (mestrado). UFES, 2001.

COSTA, Antônio C. A linguagem das trincas. Revista téchne. mar/abr, nº 03. 1993, p. 14-18. CRUZ, G. P. S. Coordenação e compatibilização de projetos para construção de edifícios: Estudos de casos em instituições públicas e privadas. Viçosa: UFV, 2011.

DUNSTON, P.S; WILLIAMSOM, C.E. Incorporating maintainiability in constructabiliy review process. Jornal of management in engineering. September/ovtober, v.15, n.5, 1999.

EBANATAW, Roberto. Fissuras e trincas. 2001. Disponível: $<\mathrm{http}$ ://www.ebanataw.com.br/roberto/patologias/trincas.htm>

FIBERSALS. Impermeabilização: conheça todas as opções existentes no mercado. FiberSals, 2018. Disponível em: https://fibersals.com.br/blog/impermeabilizacao-conheca-todas-as-opcoesexistentes-no-mercado/. 
GRILO, Leonardo M., CALMON, João L. Falhas externas em edificações segundo a percepção dos usuários. In: VIII ENTAC - Encontro nacional de tecnologia do ambiente construído. Salvador. Anais...25 a 28 de abril, 2000.

HELENE, P. R. L. Manual para reparo, reforço e proteção de estruturas de concreto. $2^{\mathrm{a}}$ ed - São Paulo: PINI, 1992.

HELENE, P.R.L., SOUZA, R. Controle da Qualidade na Indústria da Construção Civil. In: Tecnologia da edificações. Anais. São Paulo,1988, p. 537-542.

INSTITUTO BRASILEIRO de AVALIAÇÕES e PERÍCIAS de ENGENHARIA (IBAPE). Norma de inspeção predial nacional. São Paulo, 2012.

JESUS, A. A.; et.al. Comportamento Histórico no Brasil da Indústria da Construção Civil e suas Atuais Perspectivas. Revista Científica Multidisciplinar Núcleo do Conhecimento. Ano 03, Ed. 07, Vol. 05, pp. 87-95, julho de 2018.

LICHTEINSTEIN, N.B. Patologia das construções: procedimento para formulação de diagnóstico de falhas e definição de condutas adequada à recuperação de edificações. Dissertação (Mestrado). Universidade de São Paulo, São Paulo, 1985.

LYAL, Addesson. Building failures - a guide to diagnosis remedy and preventions. Third Edition. Great Britain, 1992.

OLIVEIRA, Ana M. S. S. Uma questão de falta de qualidade: incidência de manifestações patológicas em fachadas. VIII ENTAC - Encontro nacional de tecnologia do ambiente construído. Salvador. Anais...25 a 28 de abril, 2000.

ORNSTEIN, Sheila W. Avaliação Pós-Ocupação (APO) do ambiente construído. São Paulo. Studio Nobel: Editora da Universidade de São Paulo. 1992.

ROCHA, Carlos C. Paredes e trincas. Os porquês. Revista Recuperar. nov/dez, 1998.

SCHARDONG, Giana K.; PAGNUSSAT, Daniel T. Avaliação de manifestações patológicas em edificações escolares públicas. In: $7^{\circ}$. Congresso Internacional sobre Patologia e reabilitação de estruturas. Fortaleza-CE, 2 a 4 de junho de 2011. Acesso em: file://C:/Users/Usuario/Downloads/PAGNUSSAT_ARTIGO_cinpar2011.pdf

SOUZA, Paulo Renato. Recursos públicos para as universidades federais. Folha de São Paulo, 02/03/00. Disponível em: <http://www.mec.gov.br/acs/jornalis/ar_ministro/m001.shtm>.

SOUZA, R., MEKBEKIAN, G., SILVA, M.A., LEITÃO, A. N., SANTOS, M.M. Sistema de gestão da Qualidade para empresas construtoras. São Paulo. Pini, 1995.

SOUZA FILHO, Rodrigo. O controle social como instrumento político na gestão do orçamento público. III Simpósio orçamento público e políticas sociais. 17 e 18 de outubro, 2017. ISBN: 97885-7846-440-0.

THOMAZ, Ercio. As causas de fissuras. Revista téchne. set/out, no 36. 1998, p. 44-49.

THOMAZ, Ercio. Trincas em edificios - causas, prevenção e recuperação. São Paulo. Ed. Pini, USP - Universidade de São Paulo / IPT - Instituto de Pesquisas Tecnológicas, 1989, 194 p.

VERÇOSA, Enio J. Patologia da umidade. In: Simpósio sobre patologia das edificações Prevenção e recuperação. Anais... 24 e 25 de outubro de 1989. Porto Alegre, p. 174-194. 